\title{
IEDITORIAL
}

\section{QRS fragmentations as predictors of arrhythmic events}

\author{
Wojciech Zaręba \\ Cardiology Division, University of Rochester Medical Center, Rochester, New York, United States
}

\section{RELATED ARTICLE by Kucharz and Kułakowski,} see p. 1107
Correspondence to: Prof. Wojciech Zaręba, MD, $\mathrm{PhD}$, Clinical Cardiovascular Research Center, University of Rochester Medical Center, 265 Crittenden Blvd., Rochester, NY 14620, United States, phone: +15852755391, email: wojciech_zareba@urmc.rochester.edu Received: November 4, 2020. Accepted: November 5, 2020. Published online: November 25, 2020. Kardiol Pol. 2020; 78 (11): 1084-1085 doi:10.33963/KP.15687 Copyright by the Author(s), 2020
The concept of reentrant ventricular arrhythmias in the postinfarction myocardium is over 40 years old when it was recognized that conduction delays play a key role in reentrant pathways. ${ }^{1}$ Delayed activation caused by a scar, fibrosis, or ischemia could be manifested on electrocardiography (ECG) as late potentials indicating a propensity to reentrant ventricular arrhythmias and sudden cardiac death. ${ }^{2-4}$ Detection of late potentials, requiring signal-averaging to reduce signal-to-noise ratio, has been identified as risk factors for predicting mortality and arrhythmic events. ${ }^{4,5}$ Recently, the Risk Stratification in Patients With Preserved Ejection Fraction (PRESERVE EF) study demonstrated that late potentials play a key role in the multifactorial risk stratification of postinfarction patients with preserved ejection fraction who might benefit from an implantable cardioverter-defibrillator (ICD). ${ }^{6}$

QRS fragmentations, defined as notches or slurs within the QRS complex, were identified as predictors of mortality and arrhythmic events in coronary patients ${ }^{7-9}$ including patients with an ICD from the Multicenter Automatic Defibrillator Implantation Trial II (MADIT II). ${ }^{10}$ Fragmentations of QRS could be recognized by a naked eye in a standard 12-lead ECG, not requiring signal averaging, and are considered an indicator of delayed intraventricular conduction activation. Interspersed fibrosis or scarring might lead to these delays, and during suitable conditions with presence of ventricular premature beats, they could initiate reentry.

In this issue of Kardiologia Polska (Kardiol Pol, Polish Heart Journal), Kucharz and Kułakowski ${ }^{11}$ reported data on QRS fragmentation (fQRS) in a large cohort of 367 patients with an ICD implanted for primary or secondary prevention of death. Fragmented QRS was identified in 161 patients (44\%). Not surprisingly, the percentage was smaller in patients with QRS of less than $120 \mathrm{~ms}$ as compared with those with QRS of $120 \mathrm{~ms}$ or greater (25\% vs $59 \%$, respectively). During a mean 3-year follow-up, appropriate ICD therapies for ventricular tachycardia or fibrillation (VT/VF) were observed in 141 patients (38\%) and the primary endpoint (including appropriate ICD therapy or arrhythmic death) was observed in 146 patients (40\%), whereas 67 (18.3\%) died. In the multivariate analysis, the primary endpoint was predicted by: ICD implantation for secondary prevention (odds ratio, 2.13; 95\% CI, 1.13-4.025; $P=0.02$ ) and $\mathrm{fQRS}$ in inferior ECG leads (odds ratio, 4.88; $95 \%$ CI, $0.05-0.85 ; P=0.03$ ). Total mortality was not predicted by fQRS in multivariate analyses. The authors concluded that $\mathrm{fQRS}$ in inferior ECG leads is an independent factor associated with higher risk of arrhythmic events in patients with ICD. ${ }^{11}$

This interesting study with a large number of ICD patients and long-term follow-up contributes to our further understanding of factors that might predict arrhythmic events. The presence of $\mathrm{fQRS}$ on ECG (in inferior leads) might be easily spotted by clinicians who might be prompted by this finding to refer patients to an ICD for primary prevention earlier than later. However, this study lacks information regarding a predictive value of $f Q R S$ in the subgroup of $70.6 \%$ of patients with primary prevention indication for an ICD. Secondary prevention patients are eligible for prompt ICD implant and this decision will not be influenced by the presence or absence of $\mathrm{fQRS}$. However, in primary prevention patients, fQRS might be helpful in the decision process. 
Minor comments can be made regarding statistical analyses. One would expect that hazard ratios from the Cox proportional analyses should be presented instead of odds ratios coming from logistic regression, which is not a survival analysis. One would also benefit from seeing the Kaplan-Meier curves for predicting primary endpoints in the overall population as well as in a subset of patients with primary prevention ICD indications. It would also be useful to learn whether $\mathrm{fQRS}$ was predictive for VT as well as for VF, recognizing limited statistical power.

Despite these minor limitations, the study provides further evidence that $\mathrm{fQRS}$ is worth exploring in future studies. Fragmented QRS represents delays in intracardiac conduction which might predispose to ventricular tachyarrhythmias, most likely in the mechanisms of reentry. Recent meta-analyses of 10 papers focused on the prognostic significance of $\mathrm{fQRS} \mathrm{S}^{12}$ indicated that this ECG finding is associated with a relative risk of major arrhythmic events at the level of 1.74 with $95 \%$ CI between 1.09 and 2.80 , indicating statistical significance (about $74 \%$ increase in risk). In the paper by Kucharz and Kułakowski, ${ }^{11}$ the risk associated with $\mathrm{fQRS}$ is much higher, almost 5-fold what might be associated with different patient population and different methodologies assessing fQRS. Further analyses of papers describing patients with ICDs ${ }^{12}$ show relative risk of 1.57 (95\% CI, 0.902.74, therefore of borderline significance) for predicting major arrhythmic events. At the same time, the risk ratio for mortality in ICD patients was 1.36 with $95 \%$ CI from 1.08 to 1.36 .

QRS fragmentation is one of recently exercised variables in the risk stratification of mortality or appropriate ICD shocks and there is a trend toward combining such risk factors to further refine risk prediction. ${ }^{6,13}$ One also needs to recognize that some of the QRS fragmentations are very subtle and clinicians reading ECGs might miss them. Therefore, there is a need to introduce and implement automatic algorithms detecting and quantifying fragmentation, notches, and fractionation of the QRS complex. One of such algorithms was developed by our group to quantify notches and slurs in QRS to enhance automatic diagnosis of left bundle branch block qualifying patients for cardiac resynchronization therapy. ${ }^{14}$ With current trends toward digital ECG signal used by every ECG machine, there will be a possibility to implement new algorithms to automatically detect fragmented QRS.

\section{ARTICLE INFORMATION}

DISCLAIMER The opinions expressed by the author are not necessarily those of the journal editors, Polish Cardiac Society, or publisher.

CONFLICT OF INTEREST None declared.

OPEN ACCESS This is an Open Access article distributed under the terms of the Creative Commons Attribution-NonCommercial-NoDerivatives 4.0 International License (CC BY-NC-ND 4.0), allowing third parties to download articles and share them with others, provided the original work is properly cited, not changed in any way, distributed under the same license, and used for noncommercial purposes only. For commercial use, please contact the journal office at kardiologiapolska@ptkardio.pl.

HOW TO CITE Zaręba W. QRS fragmentations as predictors of arrhythmic events. Kardiol Pol. 2020; 78: 1084-1085. doi:10.33963/KP.15687

\section{REFERENCES}

1 El-Sherif N, Hope RR, Scherlag BJ, Lazzara R. Re-entrant ventricular arrhythmias in the late myocardial infarction period. 2. Patterns of initiation and termination of re-entry. Circulation. 1977; 55: 702-719.

2 El-Sherif N, Gomes JA, Restivo M, Mehra R. Late potentials and arrhythmogenesis. Pacing Clin Electrophysiol. 1985; 8: 440-462.

3 Zareba W, Pracka $\mathrm{H}, 0$ szczygieł $\mathrm{S}$, et al. Late ventricular potentials and ventricular arrhythmia in patients with stable ischemic heart disease [in Polish]. Kardiol Pol. 1990; 33: 16-22.

4 Kułakowski P. Ventricular late potentials-an important prognostic indicator [in Polish]. Kardiol Pol. 1990; 33: 31-38.

5 Kulakowski P, Malik M, Poloniecki J, et al. Frequency versus time domain analysis of signal-averaged electrocardiograms. II. Identification of patients with ventricular tachycardia after myocardial infarction. J Am Coll Cardiol. 1992; 20: $135-143$.

6 Gatzoulis KA, Tsiachris D, Arsenos P, et al. Arrhythmic risk stratification in post-myocardial infarction patients with preserved ejection fraction: the PRESERVE EF study. Eur Heart J. 2019; 40: 2940-2949.

7 Das MK, Saha C, El Masry H, et al. Fragmented QRS on a 12-lead ECG: a predictor of mortality and cardiac events in patients with coronary artery disease. Heart Rhythm. 2007; 4: 1385-1392.

8 Pietrasik G, Goldenberg I, Zdzienicka J, et al. Prognostic significance of fragmented QRS complex for predicting the risk of recurrent cardiac events in patients with Q-wave myocardial infarction. Am J Cardiol. 2007; 100: 583-586.

9 Pietrasik G, Zaręba W. QRS fragmentation: diagnostic and prognostic significance. Cardiol J. 2012; 19: 114-121.

10 Brenyo A, Pietrasik G, Barsheshet A, et al. QRS fragmentation and the risk of sudden cardiac death in MADIT II. J Cardiovasc Electrophysiol. 2012; 23: 1343-1348. 11 Kucharz A, Kułakowski P. Fragmented QRS and arrhythmic events in patients with implantable cardioverter-defibrillators. Kardiol Pol. 2020; 78: 1107-1114.

12 Kanitsoraphan C, Rattanawong P, Mekraksakit P, et al. Baseline fragmented QRS is associated with increased all-cause mortality in heart failure with reduced ejection fraction: a systematic review and meta-analysis. Ann Noninvasive Electrocardiol. 2019; 24: e12597.

13 Vandenberk B, Junttila M], Robyns $\mathrm{T}$, et al. Combining noninvasive risk stratification parameters improves the prediction of mortality and appropriate ICD shocks. Ann Noninvasive Electrocardiol. 2019; 24: e12604.

14 Xia X, Ruwald AC, Ruwald MH, et al. Validation of an automatic diagnosis of strict left bundle branch block criteria using 12-lead electrocardiograms. Ann Noninvasive Electrocardiol. 2017; 22: e12398. 